\title{
URINARY CALCIUM, MAGNESIUM, CRYSTALS AND STONES IN PARAPLEGIA
}

\author{
By R. G. BurR, M.Sc., A.R.I.C. \\ National Spinal Injuries Centre, Stoke Mandeville Hospital, \\ Aylesbury, Buckinghamshire
}

\section{INTRODUCTION}

INJURY to the spinal cord is followed by an increased urinary calcium, a factor known to be associated with the formation of stones in the upper urinary tract. Some workers (for example Freeman, 1949) have attached great importance to hypercalciuria when discussing the aetiology of kidney stones in paraplegia, but infection of the urinary tract by urea-splitting organisms is now seen to be of greater importance. There is evidence that stone disease in paraplegics is preventable by prompt and effective treatment of urinary infection (Smith et al., 1969).

Nordin et al. (1967) recognise two main types of renal stone according to whether, in addition to calcium phosphate, they contain either calcium oxalate or magnesium ammonium phosphate (MAP). The former are those associated with an increased excretion of calcium or oxalate (or both). The latter are those associated with chronic infection of the urinary tract, and most stones removed from paraplegics are of this type. The low incidence of oxalate calculi among paraplegics in the presence of hypercalciuria (often severe) has not been explained.

This study was part of an attempt to find out what part calcium plays in stone formation, and in particular to consider its possible role in stone nucleation (Vermeulen et al., I967).

\section{METHODS AND RESULTS}

Urinary Calcium and Oxalate. Two groups of patients were studied, both consisting of 27 men. The first group were patients with spinal cord lesion (I2 cervical, I2 thoracic and 3 lumbar) aged I4-59 years (mean $3 \mathrm{I} \cdot \mathrm{I}$ ), from whom 24-hr. urine specimens were collected 4-267 days (mean 53.3) after injury. The second group were non-paraplegic hospital in-patients aged I6-65 years (mean $4 \mathrm{I} \cdot 2$ ) and consisted of 17 patients admitted for minor surgery, 8 for medical investigation and 2 just prior to discharge home following treatment for burn injury. A total of 7I 24-hr. urine specimens were collected from the patients in group I and 46 from those in group II.

The urine was collected in bottles containing $\mathrm{I} 0 \mathrm{ml}$. concentrated hydrochloric acid. Calcium and magnesium were determined by atomic absorption spectrophotometry and sodium and potassium by flame photometry. Inorganic phosphate and creatinine were measured in an AutoAnalyser (Techicon Instruments Co. Ltd., Basingstoke, Hants.) and oxalate was determined by the method of Archer et al. (1957).

Table I shows the 24-hr. output and urinary concentrations of calcium and oxalate and the 24-hr. urine volumes for the two groups. The $24-\mathrm{hr}$. excretion of 
calcium and urine volumes were higher in the paraplegics than in the non-paraplegics and there was no significant difference in oxalate excretion between the two groups. The concentration in the urine of both calcium and oxalate, however, was lower in the paraplegics $(\mathrm{P}<0 \cdot 0 \mathrm{I})$.

TABLE I

Urinary Calcium and Oxalate Excretion in Hospital Patients

\begin{tabular}{|c|c|c|c|}
\hline & $\begin{array}{l}\text { Paraplegics } \\
(n=27)\end{array}$ & $\begin{array}{l}\text { Non-Paraplegics } \\
\quad(n=27)\end{array}$ & \\
\hline $\begin{array}{l}\text { Calcium (mg./24 hr.) } \\
\text { Calcium (mg./litre) }\end{array}$ & $\begin{array}{l}M \quad S D \\
348 \pm I 56 \\
I 30 \pm 54\end{array}$ & $\begin{array}{l}M \quad S D \\
276 \pm 98 \\
199 \pm 83\end{array}$ & $\begin{aligned} 0.02 & <\mathrm{P}<0.05 \\
0.001 & <\mathrm{P}<0.01\end{aligned}$ \\
\hline $\begin{array}{l}\text { Oxalate (mg./24 hr.) } \\
\text { Oxalate (mg./litre) }\end{array}$ & $\begin{array}{r}13 \cdot 3 \pm 7 \cdot 2 \\
5 \cdot 9 \pm 4 \cdot 2\end{array}$ & $\begin{array}{l}\mathrm{I} 4 \cdot 4 \pm 7 \cdot \mathrm{I} \\
\mathrm{II} \cdot \mathrm{I} \pm 8 \cdot 6\end{array}$ & $\begin{array}{l}\text { Not significant } \\
0.00 \mathrm{I}<\mathrm{P}<0.0 \mathrm{I}\end{array}$ \\
\hline Volume (ml./24 hr.) & $2940 \pm$ I I96 & $1655 \pm 756$ & $\mathrm{P}<0.00 \mathrm{I}$ \\
\hline
\end{tabular}

P obtained using Student's $t$ test.

TABLE II

Urinary Excretion in Hospital Patients

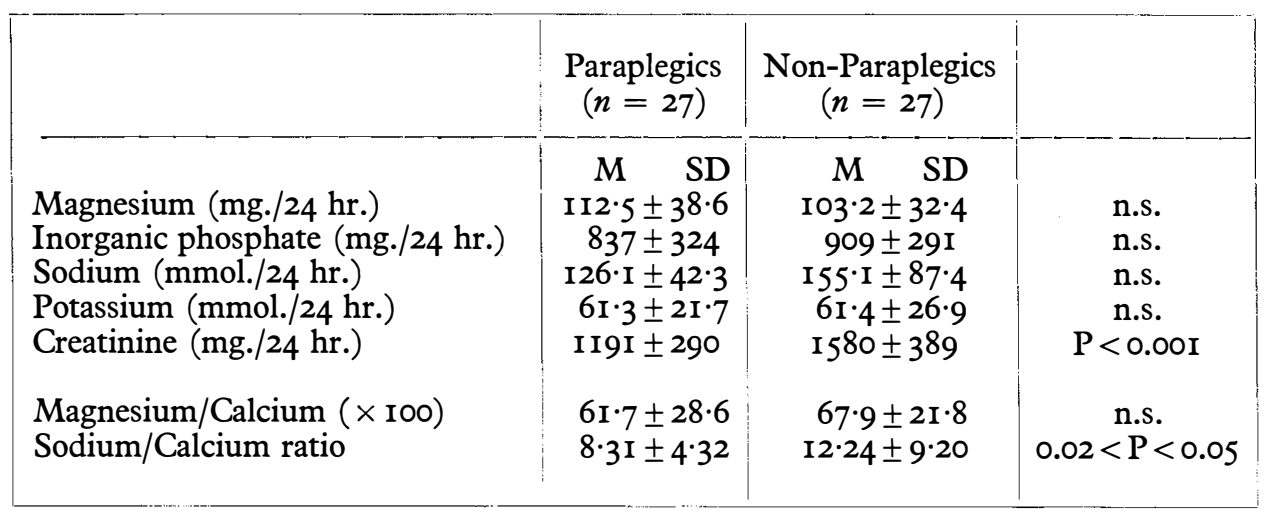

P obtained using Student's $t$ test.

n.s. $=$ Not significant.

Table II shows the excretion of magnesium, inorganic phosphate, sodium, potassium and creatinine for the two groups, and also the ratios of magnesium to calcium and of sodium to calcium. The differences between paraplegic and nonparaplegic hospital patients were significant in the case of creatinine excretion $(\mathrm{P}<0.00 \mathrm{I})$ and of the sodium $/$ calcium ratio $(0.02<\mathrm{P}<0.05)$. 
TABLE III

Crystalluria in Hospital Patients

\begin{tabular}{|l|c|c|c|} 
& Paraplegics & Non-Paraplegics & \\
\hline Patients-Total & 2687 & 7728 & \\
Patients-Oxalate crystals & $375(\mathrm{I} 4.0 \%)$ & $\mathrm{I} 509(\mathrm{I} 9 \cdot 7 \%)$ & $\mathrm{P}<0.00 \mathrm{I}$ \\
Patients-MAP crystals & $33 \mathrm{I}(\mathrm{I} 2 \cdot 3 \%)$ & $343(4.4 \%)$ & $\mathrm{P}<0.00 \mathrm{I}$ \\
& & & \\
Specimens-Total & $\mathrm{I} 7,558$ & 20,510 & \\
Specimens-Oxalate crystals & $683(3.9 \%)$ & $\mathrm{I} 9 \mathrm{I} 8(9.4 \%)$ & $\mathrm{P}<0.00 \mathrm{I}$ \\
Specimens-MAP crystals & $566(3.2 \%)$ & $547(2.7 \%)$ & $0.00 \mathrm{I}<\mathrm{P}<0.0 \mathrm{I}$ \\
& & & \\
\hline
\end{tabular}

P obtained Jby calculating the standardised normal deviate.

$\mathrm{MAP}_{\vec{i}}=$ magnesium ammonium phosphate.

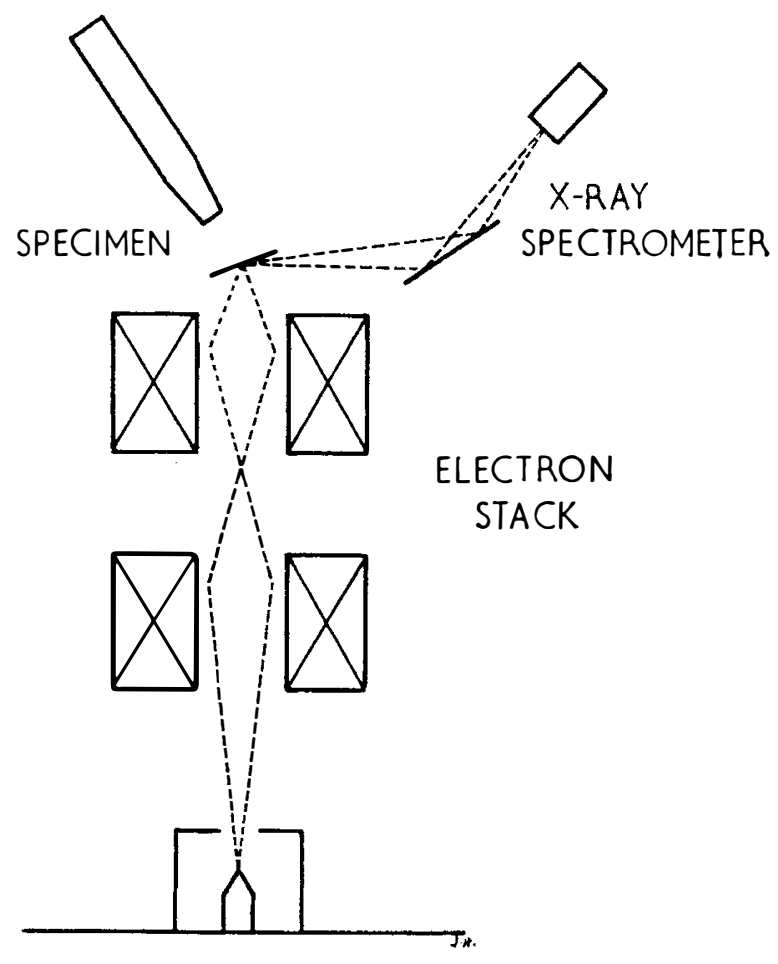

\section{ELECTRON MICROPROBE ANALYSER}

FIG. I

Schematic diagram. 
Crystalluria. Table III shows the results of a search of the records of the Bacteriology Department of the Hospital. Reports of routine miscroscopy of urine specimens from paraplegic patients (including male and female, in-patients and out-patients at all stages of the condition) are compared with those of non-paraplegic hospital patients (including male and female, medical and surgical, inpatients and out-patients; together with specimens sent by General Practitioners and from Ante-natal Clinics). Fewer oxalate crystals, but more MAP crystals, were reported in the urine specimens from paraplegics than in those from nonparaplegics, whether this was calculated from the number of patients who at any time exhibited crystalluria (Table III, top) or from the total number of specimens examined (bottom).

Microprobe Analysis of Stones. Electron microprobe analysis is a method used by geologists to examine rock samples. The apparatus is shown diagrammatically in Figure I. A section of rock is cut and one surface highly

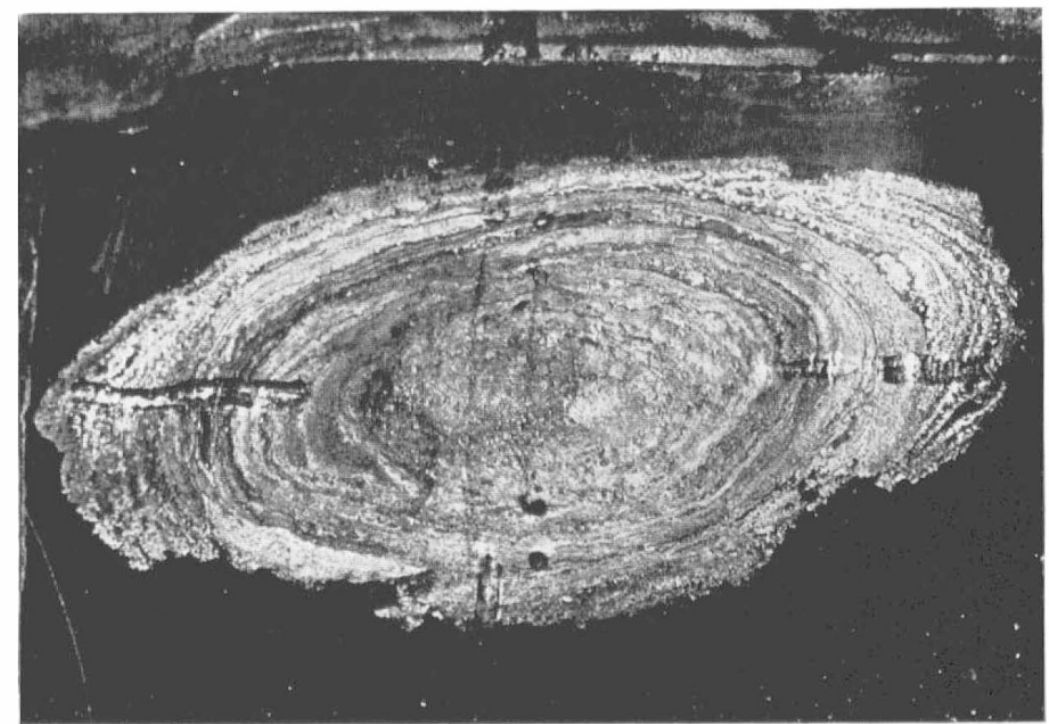

FIG. 2

Section of a ureteric stone.

polished. A layer of carbon is evaporated on to the surface to prevent it becoming electrically charged. A beam of electrons is focussed on the surface to a spot $\mathrm{I} \mu \mathrm{m}$. diameter. X-rays are emitted, the wavelengths of which are characteristic of the elements (e.g. calcium, magnesium or phosphorus) present in the specimen. Their intensity indicates the concentrations.

Figure 2 shows a section of a ureteric stone. The three slightly curved dark lines (two vertical, one horizontal) which cross the centre were made by passage of the electron spot, and caused by local heating and charring.

Figure 3 shows the tracings obtained by scanning this section for calcium, magnesium and phosphorus. Of particular interest is the part marked with an arrow at which the calcium concentration falls almost to zero, there is no apparent change 
in the phosphorus concentration, but the magnesium concentration is so high that the tracing is off the scale. This region measures $200 \mu \mathrm{m}$. approximately. The finding indicates the presence of a zone of MAP near to the centre of a stone which

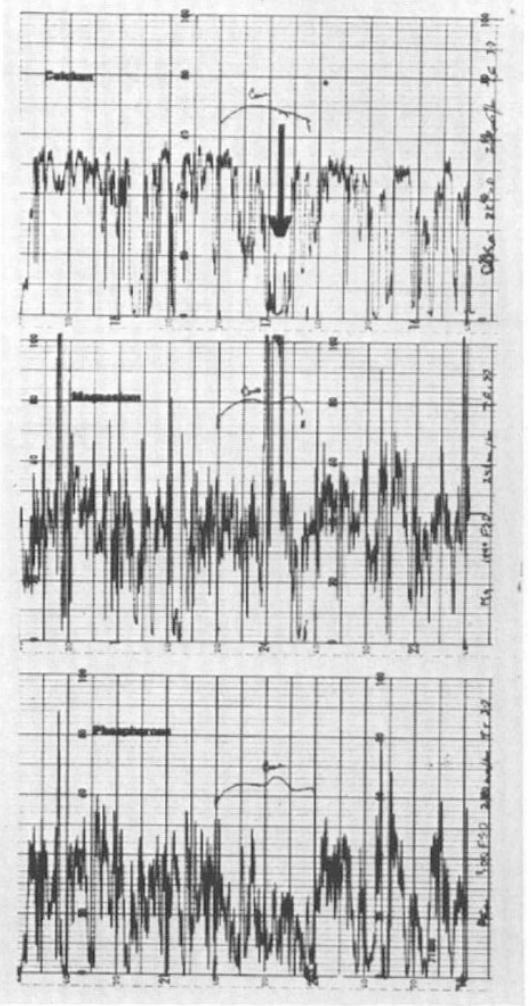

FIG. 3

Electron microprobe records for the section shown in Figure 2. Top, calcium; Centre, magnesium; Bottom, phosphorus. The position of the high magnesium/low calcium zone is marked by an arrow.

consists of a mixture of MAP, calcium phosphate and a trace of carbonate. To date, three stones have been examined and the appearance described seen in two of them.

\section{DISCUSSION}

The mean 24-hr. output of calcium for the group of paraplegics studied (Table I) was lower than that obtained previously from other groups of paraplegics. Thus the mean calcium excretion of a group of 50 male patients studied by the collection of $24-\mathrm{hr}$. urine specimens for five consecutive days beginning six weeks after injury was $432 \mathrm{mg} . / 24 \mathrm{hr}$. (unpublished observations). The urinary calcium excretion of the present group of paraplegics was, however, higher than the figures quoted by other workers for groups of patients with renal stones of the oxalate type. Such figures include: I62 mg. $/ 24 \mathrm{hr}$. (Modlin, I967), I76 mg. $/ 24 \mathrm{hr}$. (Hunt \& King, I963) and $326 \mathrm{mg} .24 \mathrm{hr}$. (Robertson et al., I968). Higher figures have, however, been obtained by Evans et al. (1967) (380 mg./24 hr.) and by Phillips and Cooke (I967) (444 mg./24 hr.). 
Modlin (1967) suggested the use of the urinary sodium to calcium ratio to distinguish patients with renal stones from control subjects, and obtained a mean ratio of I7.I for the former and 43.I for the latter. Oreopoulos et al. (I968) studied the magnesium to calcium ratio and obtained a value of 89.3 for control subjects and $44 \cdot 8$ for stone patients. Such ratios depend on ionic interactions in urine for their significance (Modlin, I968).

The urinary calcium excretion of the paraplegics studied was greater than that of the non-paraplegic patients, and the sodium/calcium ratios were lower for the paraplegics than for the non-paraplegics. It follows that if these factors are applicable there should be a higher incidence of oxalate calculi in paraplegic patients than in others. The urine volumes of the paraplegic patients were so large, however, that their urines were more dilute than those of the non-paraplegic patients. Thus the concentrations of both calcium and oxalate were lower in the paraplegics than in the non-paraplegics. These figures presumably reflect the effect of a high fluid intake in the paraplegics and may explain the low incidence of oxalate calculi in such patients.

The need to maintain a dilute urine while the calcium output is increased (about six months for a paraplegic and 12 months for a tetraplegic) is well known. A high fluid intake may be particularly important if $\mathrm{G}_{500^{1}}$ is given since this has the effect of increasing calcium excretion in acute paraplegics (unpublished observations).

Another situation in which the maintenance of a high fluid intake may be important is if ascorbic acid is given in doses greater than $4 \mathrm{~g}$. per day, because this is known to increase the excretion of oxalate in healthy subjects (Lamden \& Chrystowski, I954).

A reduction in the urinary excretion of creatinine following paralysis was noted by Whedon et al. (I957) and thought to be related to the decline in muscle mass. Renal function as measured by endogenous creatinine clearance is generally normal in acute paraplegics (Doggart et al., I966).

The figures obtained from records of routine microscopic examination of urine specimens must be interpreted with caution since crystals are reported only as an incidental finding. In general, such crystals are not present in urine when passed but appear on standing. Their appearance does, however, serve to indicate the state of saturation. Statistically, the figures given in Table II are highly significant, and are what we would expect if the urines of the paraplegics were more dilute but more prone to infection than those of the non-paraplegic patients.

Electron microprobe analysis has limitations when applied to urinary stones because they are much softer than rock and therefore cannot be polished sufficiently by existing techniques. This is the reason for the very noisy tracing seen in Figure 3. In addition the position of the nucleus, if any, cannot be determined before the section is cut or the scan is made. The existence of a region of concentrated MAP near the centre of a mixed phosphate stone is of great interest. Such a region may represent a nucleus around which the stone has grown.

The formation of a stone requires the production of a nucleus, retention of the potential stone embryo within the urinary tract, and its growth into a stone. The growth of stones containing MAP is known to be associated with infection by urea-splitting organisms. Stone initiation has been variously attributed to

${ }^{1}$ G500: Each tablet contains 0.25 g. hexamine mandelate +0.25 g. methionine (Ward Blenkinsop Pharmaceuticals Ltd., Wembley, Middx.). 
desquamated urinary tract epithelium such as may appear in hypovitaminosis A, clumps of bacteria, an autoimmune mechanism, or aggregations of crystals in the form of a Randall's plaque or a Carr's pouch. Increased transport of calcium leading to increased secretion of uromucoid or to a lesion of the renal tubules has also been suggested. The simplest hypothesis applicable to all types of stone disease is that of a 'hyperexcretion-crystallisation' mechanism. There is good evidence for such a mechanism in the case of cystine, uric acid and calcium oxalate calculi (Robertson et al., I97I).

This work was begun with the hypothesis that in paraplegia a suitable nucleus may be provided by calcium oxalate precipitated during the hypercalciuric phase. Subsequent infection might then lead to epitaxic growth of a mixed phosphate stone. The results provide no evidence for this. Instead they indicate the possibility that in some cases nucleation may be due to precipitation of MAP.

Magnesium is poorly absorbed following oral administration (Todd, I967) but was absorbed sufficiently to cause elevation of plasma magnesium in ten subjects receiving oral magnesium hydroxide (Wallach et al., 1962). One patient in this centre taking magnesium trisilicate (not containing sodium bicarbonate) ad libitum was found to be passing a very cloudy urine containing 372 and $408 \mathrm{mg}$. magnesium per $24 \mathrm{hr}$. (on successive days). On stopping the medication, the urine became clear and the magnesium excretion fell to I $32 \mathrm{mg} . / 24 \mathrm{hr}$. Magnesium is a major component of all bladder stones and of most kidney stones occurring in paraplegics. Its use may be inadvisable when the urine contains urea-splitting organisms such as those of the Proteus group.

\section{SUMMARY}

The concentrations in urine of calcium and of oxalate were lower in a group of acute paraplegic and tetraplegic patients than in a group of non-paraplegic hospital in-patients. Twenty-four-hour urine volumes and excretion of calcium were higher in the paraplegic and tetraplegic patients and the 24 -hr. oxalate excretion did not differ significantly between the two groups. Examination of hospital records of routine bacteriological examination revealed that the occurrence of calcium oxalate crystals was less, and of magnesium ammonium phosphate greater, in urine specimens from paraplegics than in those from non-paraplegic hospital patients. Results of electron microprobe analyses of three upper urinary tract stones from paraplegic patients indicated the presence in two of them of a region near the centre measuring $200 \mu \mathrm{m}$. across and consisting of a high concentration of magnesium ammonium phosphate. Some therapeutic implications of these findings are discussed.

Acknowledgments. The author wishes to thank Dr. A. Barr for the statistical analyses; Sqdn.-Ldr. A. Broughton and the staff of the R.A.F. Institute of Pathology and Tropical Medicine, Halton, Aylesbury for the urinary calcium, magnesium, phosphate and creatinine analyses; Dr. C. L. Greenbury for access to the records of the Bacteriology Department; Mrs. I. Kardos for invaluable technical assistance; Dr. J. Vernon for drawing attention to the patient taking magnesium trisilicate; and Professor E. A. Vincent and the staff of the Department of Geology and Mineralogy, University of Oxford for the Electron Microprobe Analyses. 


\section{REFERENCES}

Archer, H. E., Dormer, A. E., Scowen, E. F. \& Watts, R. W. E. (1957). Clin. Sci. 16, 405 .

Doggart, J. R., Guttmann, L. \& Silver, J. R. (I966). Paraplegia, 3, 229.

Evans, R. A., Forbes, M. A., Sutton, R. A. L. \& Watson, L. (1967). Lancet, 2, 958.

FREEMAN, L. W. (I949). Ann. Surg. I29, I77.

HunT, L. D. \& KING, J. S. (I963). Invest. Urol. I, 83.

Lamden, M. P. \& Chrystowski, G. A. (1954). Proc. Soc. exper. Biol. Med. 85, 190.

Modlin, M. (1967). Ann. Roy. Coll. Surg. 40, I55.

ModiIn, M. (I968). Lancet, 2, 734.

Nordin, B. E. C. \& Hodgkinson, A. (I967). Adv. Int. Med. 13, I55.

Nordin, B. E. C., Hodgkinson, A., PeACock, M. \& Robertson, W. G. (1969). Fifth Symposium on Advanced Medicine. Ed. R. Williams. Pitman, London.

Oreopoulos, D. C., Soyannwo, M. A. O. \& McGeown, M. G. (1968). Lancet, 2, 420.

Phillips, M. J. \& Cooke, J. M. C. (1967). Lancet, I, I354.

Robertson, W. G., Peacock, M. \& Nordin, B. E. C. (1968). Clin. Sci. 34, 579.

Robertson, W. G., Peacock, M. \& Nordin, B. E. C. (I97i). Clin. Sci. 40, 365.

Smith, P. H., Cook, J. B. \& Robertson, W. G. (I969). Paraplegia, 7, 77.

TodD, R. G. (1967). Ed. Extra Pharmacopoeia Martindale, 25th Edition. The Pharmaceutical Press, London.

Vermeulen, C. W., Lyon, E. S., Ellis, J. E. \& Borden, T. A. (1967). F. Urol. 97, 573.

Wallach, S., Cahill, L. N., Rogan, F. H. \& Jones, H. L. (I962). F. Lab. clin. Med. 59, I95.

Whedon, G. D., Shorr, E., Toscani, V. \& Stevens, E. (I957). F. clin. Invest. 36, 942. 